Article

\title{
Calcium Chloride Modified Alginate Microparticles Formulated by the Spray Drying Process: A Strategy to Prolong the Release of Freely Soluble Drugs
}

\author{
Marta Szekalska * (D), Katarzyna Sosnowska ${ }^{(D)}$, Anna Czajkowska-Kośnik ${ }^{(D)}$ and \\ Katarzyna Winnicka * (D) \\ Department of Pharmaceutical Technology, Medical University of Białystok, Mickiewicza 2c, \\ 15222 Białystok, Poland; katarzyna.sosnowska@umb.edu.pl (K.S.); anna.czajkowska@umb.edu.pl (A.C.-K.) \\ * Correspondence: marta.szekalska@umb.edu.pl (M.S.); kwin@umb.edu.pl (K.W.); Tel.: +48-85-748-5616 (M.S.) \\ Received: 18 July 2018; Accepted: 21 August 2018; Published: 24 August 2018 \\ check for \\ updates
}

\begin{abstract}
Alginate (ALG) cross-linking by $\mathrm{CaCl}_{2}$ is a promising strategy to obtain modified-release drug delivery systems with mucoadhesive properties. However, current technologies to produce $\mathrm{CaCl}_{2}$ cross-linked alginate microparticles possess major disadvantages, such as a poor encapsulation efficiency of water-soluble drugs and a difficulty in controlling the process. Hence, this study presents a novel method that streamlines microparticle production by spray drying; a rapid, continuous, reproducible, and scalable technique enabling obtainment of a product with low moisture content, high drug loading, and a high production yield. To model a freely water-soluble drug, metformin hydrochloride (MF) was selected. It was observed that MF was successfully encapsulated in alginate microparticles cross-linked by $\mathrm{CaCl}_{2}$ using a one-step drying process. Modification of ALG provided drug release prolongation-particles obtained from $2 \%$ ALG cross-linked by $0.1 \% \mathrm{CaCl}_{2}$ with a prolonged MF rate of dissolution of up to $12 \mathrm{~h}$. Cross-linking of the ALG microparticles structure by $\mathrm{CaCl}_{2}$ decreased the swelling ratio and improved the mucoadhesive properties which were evaluated using porcine stomach mucosa.
\end{abstract}

Keywords: polymer cross-linking; alginate modification; calcium chloride; microparticles; spray drying; prolonged drug release

\section{Introduction}

Polysaccharides are polymeric carbohydrate molecules commonly exploited in the design of pharmaceutical formulations with prolonged drug release. These polymers possess many advantages such as non-toxicity, wide availability, simplicity to receive, and gelling ability using different cross-linking agents [1]. Sustained release formulations enable a prolonged release profile, which reduces the frequency of drug applications, minimizes side effects, and improves patient's compliance [2,3]. Dosage forms with mucoadhesive properties provide continuous contact with the mucosal membrane and as a consequence, a prolonged drug residence time and improved drug absorption and bioavailability can be achieved $[4,5]$. Mucoadhesive microparticles are an example of multi-unit carriers, where the active substance is incorporated in a natural or synthetic polymer matrix. Additionally, microparticles are characterized by a high surface area of drug release and short diffusion pathway, which enables the improvement of the therapeutic efficacy and a reduction of the drug toxicity $[6,7]$.

Sodium alginate (ALG) is a non-toxic polymer which naturally occurs in seaweeds. It may also be synthesized by Azotobacter and Pseudomonas bacteria [8,9]. ALG is a polysaccharide consisting of $\beta$-D-mannuronic and $\alpha$-L-guluronic acid residues linked by (1-4) glycosidic bonds. ALG is a 
biocompatible, nonirritant polymer with favorable swelling, gelling, and mucoadhesive properties, thus, it has a wide range of applications in drug delivery technology. ALG hydrogels can be obtained by various cross-linking methods, such as ionic modification ("egg-box" model) based on the binding of cations by the guluronate. In ionic cross-linking, $\mathrm{CaCl}_{2}$ is commonly exploited $[10,11]$. The cross-linking of water-soluble ALG enables an improvement in the polymer stability. Hence, $\mathrm{CaCl}_{2}$ cross-linked ALG has been widely examined as a material for pharmaceutical formulations. Additionally, an important feature of $\mathrm{CaCl}_{2}$ cross-linking is that the process can be conducted in an aqueous environment at a low temperature, and that both macromolecular and low molecular weight therapeutic agents can be encapsulated [12-15]. Cross-linked ALG is also utilized in biomedicine-in cell encapsulation or tissue engineering [16-18]. The commonly used and well-described method to obtain ALG microparticles cross-linked by $\mathrm{CaCl}_{2}$ is the internal gelation by emulsification method [19-22]. Major disadvantages of microparticles obtained by this technique include poor encapsulation efficiency of water-soluble drugs, low production yield, and organic solvent residues [8,23-25].

The spray-drying technique is a useful and valuable method to formulate spherical particles with low moisture content, high drug loading, and high production yield [25-28]. Therefore, in the present study, the opportunity of using a one-step drying process to formulate modified ALG microparticles was evaluated. As the slow release of active substances with high water solubility is a great challenge in pharmaceutical formulation designing, in the next step the influence of cross-linking on the metformin hydrochloride (MF) release, swelling, and mucoadhesive properties of designed microparticles was determined [2,3]. MF-a biguanide methyl derivative widely used as a first-line drug in non-insulin dependent diabetes mellitus was used as a model of a freely soluble drug [29].

\section{Materials and Methods}

\subsection{Materials}

Metformin hydrochloride (MF) was a product of Debao Fine Chemical CO (Henan, China). Sodium alginate (ALG) (with viscosity $132.6 \mathrm{mPa} \cdot \mathrm{s}$ of $2 \%$ solution), mucin, and gelatin were purchased from Sigma Aldrich (Steinheim, Germany). Potassium dihydrogen phosphate, sodium hydroxide, hydrochloric acid, methanol, propan-1,2-diol, acetonitrile, and calcium chloride were from Chempur (Piekary Ślaskie, Poland). Water was purified by osmosis system, Milli-Q Reagent Water System (Billerica, MA, USA). Porcine stomach mucosa was derived from the local veterinary service.

\subsection{Formulation of $\mathrm{CaCl}_{2}$ Modified ALG Microparticles}

After preliminary studies, to prepare the microparticles: $\%(w / w)$ ALG, and drug:polymer ratio 2:1 was selected, see Table 1 [30], in addition to $0.5 \%, 0.1 \%$ and $0.05 \%(w / w) \mathrm{CaCl}_{2}$ were applied. In the first step, ALG solutions were prepared and poured into the $\mathrm{CaCl}_{2}$ solution, after which their viscosity was determined using a rotational viscometer (Viscotester E Plus-Thermo Haake, Karlsruhe, Germany) [31]. The parameters of the spray-drying process (Mini Spray Dryer B-290, Büchi, Flawil, Switzerland) were set as follows: Flow rate of $4.5 \mathrm{~mL} / \mathrm{min}$, spray rate of $37 \mathrm{~m}^{3} / \mathrm{h}$, and spray flow of $600 \mathrm{~L} / \mathrm{h}$. The inlet and outlet temperatures were $115{ }^{\circ} \mathrm{C}$ and $46^{\circ} \mathrm{C}$, respectively. As a control, non-modified ALG microparticles (formulation C) were applied.

Table 1. Components of designed microparticles formulations.

\begin{tabular}{cccc}
\hline Formulation & $\mathbf{A L G}^{\mathbf{1}} \mathbf{( \% )}$ & $\mathbf{M F}^{2} \mathbf{: A L G}^{\mathbf{1}}$ Ratio & $\mathbf{C a C l}_{\mathbf{2}} \mathbf{( \% )}$ \\
\hline C & 2 & $2: 1$ & - \\
PCA1 & 2 & - & 0.1 \\
PCA2 & 2 & - & 0.05 \\
CA1 & 2 & $2: 1$ & 0.1 \\
CA2 & 2 & $2: 1$ & 0.05 \\
\hline \multicolumn{4}{c}{}
\end{tabular}




\subsection{Evaluation of Microparticles}

\subsubsection{Shape and Size}

To characterize shape and morphology of the microparticles, a scanning electron microscope (SEM) (Hitachi S4200, Tokyo, Japan) was utilized. The size distribution of microparticles suspended in propane-1,2-diol was examined by a Zetasizer NanoZS90 (Malvern Instruments, Malvern, UK) using at least three repetitions for each sample.

\subsubsection{High Performance Liquid Chromatography (HPLC) Assay}

MF concentration was studied by the HPLC method using an Agilent Technologies 1200 system (Agilent, Waldbronn, Germany) and a Waters Spherisorb ${ }^{\circledR} 5.0 \mu$ M ODS $4.6 \times 250 \mathrm{~mm}, 5 \mu \mathrm{m}$ column (Waters Corporation, Milford, MA, USA). As the mobile phase, an acetonitrile: methanol: phosphate buffer $\mathrm{pH} 3.0(20: 20: 60, v / v)$ with a flow rate of $1.0 \mathrm{~mL} / \mathrm{min}$ was exploited [30].

\subsubsection{Drug Encapsulation}

To assess MF loading, $20 \mathrm{mg}$ of microparticles was dissolved in $10 \mathrm{~mL}$ of phosphate buffer $\mathrm{pH} 6.8$. After $24 \mathrm{~h}$ of agitation in a water bath, solutions were filtrated, analyzed by the HPLC method [30], and drug loading (L) was calculated from the expression:

$$
\mathrm{L}=\mathrm{Q}_{\mathrm{m}} / \mathrm{W}_{\mathrm{m}} \times 100
$$

where $Q_{m}$-drug encapsulated in the microparticles, and $W_{m}$-microparticles weight.

Drug encapsulation efficiency (EE) was computed from the formula:

$$
\mathrm{EE}=\mathrm{Q}_{\mathrm{a}} / \mathrm{Q}_{\mathrm{t}} \times 100
$$

where $Q_{a}$ - actual drug content, $Q_{t}$ 一theoretical drug content.

Yield of production $(\mathrm{Y})$ was determined based on the equation:

$$
\mathrm{Y}=\mathrm{W}_{\mathrm{m}} / \mathrm{W}_{\mathrm{t}} \times 100
$$

where $\mathrm{W}_{\mathrm{m}}$-microparticles weight, $\mathrm{W}_{\mathrm{t}}$-theoretical calculated drug and polymer weight.

\subsubsection{Zeta Potential}

Directly after microparticles were suspended in propane-1,2-diol, Zeta potential values were determined by Zetasizer NanoZS90 (Malvern Instruments, Malvern, UK) using Zetasizer Software 6.20.

\subsubsection{Swelling Characteristics}

The swelling ratio (SR) was tested at $37 \pm 1{ }^{\circ} \mathrm{C}$ in $0.1 \mathrm{M} \mathrm{HCl}(\mathrm{pH}=1.2)$ based on the expression [32]:

$$
\mathrm{SR}=\mathrm{W}_{\mathrm{S}}-\mathrm{W}_{0} / \mathrm{W}_{0} \times 100
$$

where $\mathrm{W}_{0}$-microparticles weight, $\mathrm{W}_{\mathrm{S}}$ - swollen microparticles weight.

\subsubsection{Mucoadhesiveness}

Mucoadhesive properties were evaluated at $37 \pm 1{ }^{\circ} \mathrm{C}$ by a TA. XT. Plus Texture Analyzer (Stable Micro Systems, Godalming, UK). Gelatin, mucin, and porcine stomach mucosa were used as mucoadhesive layers [33]. Process parameters, chosen during preliminary tests, were as follows: Pretest speed $0.5 \mathrm{~mm} / \mathrm{s}$, test speed $0.1 \mathrm{~m} / \mathrm{s}$, contact time $180 \mathrm{~s}$, post-test speed $0.1 \mathrm{~mm} / \mathrm{s}$, applied force $1 \mathrm{~N}$. Mucoadhesiveness was expressed as the detachment force $\left(F_{\max }\right)$ and the work of mucoadhesion $\left(\mathrm{W}_{\mathrm{ad}}\right)$. 


\subsection{MF Dissolution}

MF dissolution from microparticle formulations (in the amount equivalent to $500 \mathrm{mg}$ of MF) was performed at $37 \pm 1{ }^{\circ} \mathrm{C}$ in a basket apparatus (Erweka Dissolution Tester Type DT 600HH, Heusenstamm, Germany) in $500 \mathrm{~mL}$ of $0.1 \mathrm{M} \mathrm{HCl}(\mathrm{pH}=1.2)$ [34]. MF concentration in the release medium was studied by the HPLC technique (as described in the point 2.3.2. HPLC analysis).

\subsection{Mathematical Modeling of the MF Release Profile}

To explain the drug release mechanism, data obtained from MF release tests were studied under different mathematical models [35,36]. Zero order kinetic:

$$
\mathrm{F}=\mathrm{k} \times \mathrm{t}
$$

first order kinetic:

$$
\ln \mathrm{F}=\mathrm{k} \times \mathrm{t}
$$

Higuchi model:

$$
\mathrm{F}=\mathrm{kt}^{1 / 2}
$$

Korsmeyer-Peppas model:

$$
\mathrm{F}=\mathrm{kt}^{\mathrm{n}}
$$

Hixson-Crowell model:

$$
1-(1-F)^{1 / 3}=\mathrm{kt}
$$

where $\mathrm{F}$ - the fraction of released drug, $\mathrm{k}$ - the constant connected with release, and $\mathrm{t}$ - the time.

\subsection{Index of Similarity and Dissimilarity}

To compare release profiles of designed microparticles, a model utilizing a difference factor $f_{1}$ and similarity factor $f_{2}$ was applied. The difference index $f_{1}$ was calculated by the formula:

$$
f_{1}=\left\{\left(\sum=1 \mathrm{n}\left|\mathrm{R}_{\mathrm{t}}-\mathrm{T}_{\mathrm{t}}\right|\right)\left(\sum=1 \mathrm{n} \mathrm{R}_{\mathrm{t}}\right)\right\} \times 100
$$

where $n$-number of samples, $R_{t}$ and $T_{t}$-data of drug dissolution of control and test sample at the same time ( $\mathrm{t}$ ). The difference index $f_{1}$ expresses the percent variation between release from the studied and control sample. The similarity index $f_{2}$ indicates the potential release similarity and it is calculated by the following equation:

$$
f_{2}=50 \times \log \left\{\left[1+(1 / n) \sum=1 n\left(R_{t}-T_{t}\right) \times 2\right]-0.5 \times 100\right\}
$$

$f_{2}$ between $50-100$ indicates release profiles similarity between samples [37-39].

\subsection{Differential Scanning Calorimetry (DSC)}

Measurements were performed using an automatic thermal analyzer system (DSC TEQ2000, TA Instruments, New Castle, DE, USA). Samples (in the amount of $5 \mathrm{mg}$ ) were placed in aluminum pans and heated in the range $25-280{ }^{\circ} \mathrm{C}$ under a $20 \mathrm{~mL} / \mathrm{min}$ nitrogen flow [40].

\subsection{Statistics}

Data were assessed by Statistica 10.0 (StatSoft, Tulsa, OK, USA) using one-way analysis of variance (ANOVA) or a Kruskal-Wallis test. Obtained results were presented as the mean and standard deviation. 


\section{Results and Discussion}

ALG is a polymeric material commonly utilized in the design of sustained drug delivery systems via its in situ gelation when in contact with the acidic stomach environment. As a result of hydrogen bonding, ALG alternates into insoluble alginic acid, which controls water penetration and prevents matrix disintegration. Additionally, to improve the mechanical strength of ALG and to reduce the solubility in water, a cross-linking process by ionic interactions with divalent cations such as $\mathrm{Ca}^{2+}$ can be performed [41]. The gelation process is a result of the linkage by $\mathrm{Ca}^{2+}$ of guluronate regions in one ALG backbone with a similar region in another ALG molecule, which creates a cross-linked structure. Application of a cross-linking agent leads to a reduction in the solubility of the polymer matrix under acidic conditions, which could be an effective approach to sustain the release of freely water-soluble drugs [42-44]. A Schematic structure of the non-modified and $\mathrm{CaCl}_{2}$ cross-linked formulation with MF is presented in Figure 1.

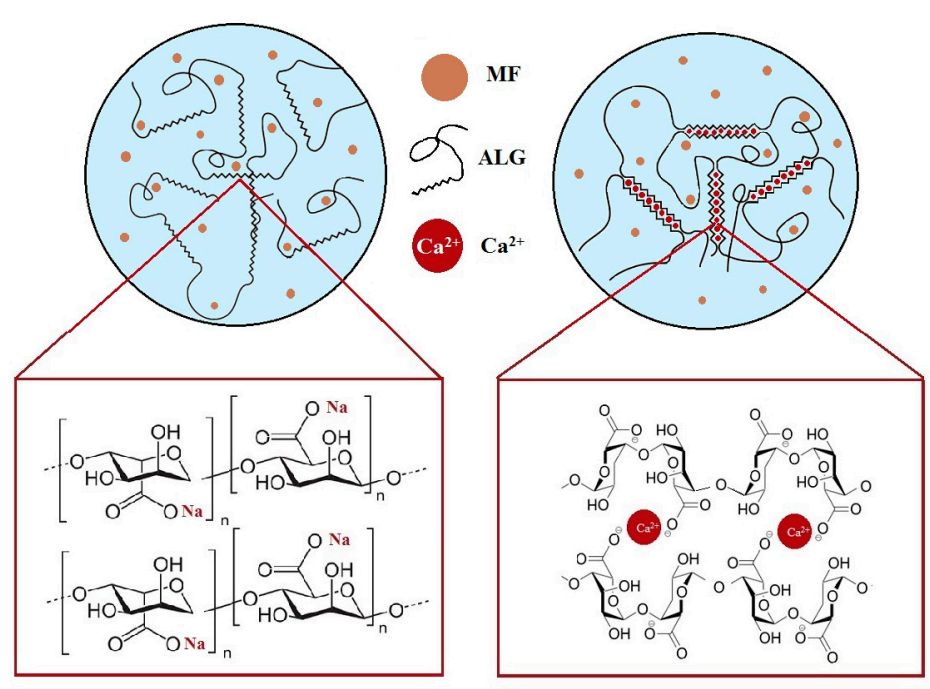

(a)

(b)

Figure 1. Structure of non-modified (a) and $\mathrm{CaCl}_{2}$ cross-linked (b) ALG microparticles containing MF.

\subsection{Microparticles Characteristics}

To receive $\mathrm{CaCl}_{2}$ modified ALG microparticles, $2 \%$ ALG and $0.05 \%$ or $0.1 \% \mathrm{CaCl}_{2}$ solutions were chosen for the one-step spray-drying process. A $2 \%$ ALG solution modified with $0.5 \% \mathrm{CaCl}_{2}$ possessed a high viscosity and its spray drying was limited, see Table 2.

Table 2. Viscosity of $\mathrm{CaCl}_{2}$ cross-linked ALG solutions.

\begin{tabular}{cc}
\hline Solution & Viscosity (mPa.s) $^{\mathbf{1}}$ \\
\hline $2 \%$ ALG & $132.6 \pm 2.7$ \\
$0.5 \% \mathrm{CaCl}_{2}+2 \%$ ALG & $4700.4 \pm 14.5$ \\
$0.1 \% \mathrm{CaCl}_{2}+2 \%$ ALG & $1600.6 \pm 12.4$ \\
$0.05 \% \mathrm{CaCl}_{2}+2 \%$ ALG & $791.7 \pm 5.3$ \\
\hline \multicolumn{2}{c}{$\mathrm{n}=3}$.
\end{tabular}

The quality evaluation of obtained microparticles included analysis of particle size, MF percent loading, drug encapsulation efficiency, production yield, and Zeta potential, see Table 3 . The morphology of microparticles formulation CA1 is presented in Figure 2. 


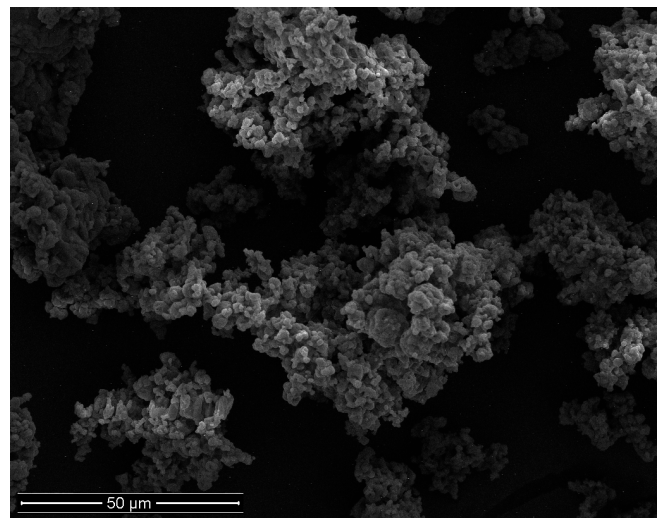

(a)

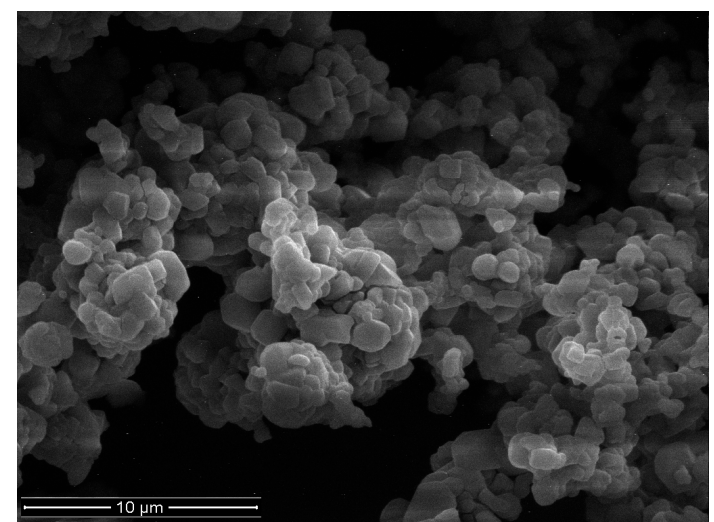

(b)

Figure 2. Images of microparticles CA1 (a) $\times 2000,(\mathbf{b}) \times 10000$.

Obtained data revealed that the cross-linking agent induced only a slight increase in the mean diameter of the microparticles (from $3.0 \pm 1.6 \mu \mathrm{m}$ in formulation C to $3.5 \pm 1.2 \mu \mathrm{m}$ in CA1) and ALG modification by $\mathrm{CaCl}_{2}$ cross-linking resulted in a small decline in production yield. Interestingly, ALG modification did not influence MF loading percentage in the microparticles, and all formulations were characterized by a drug loading of above $70 \%$, as shown in Table 3. Additionally, it was observed that the cross-linking process resulted in a slight reduction in the encapsulation efficiency (from $113.4 \pm 2.3 \%$ in formulation $C$ to $91.5 \pm 2.1 \%$ in CA1).

ALG is an anionic polymer with a negative charge, but positively charged MF and $\mathrm{Ca}^{2+}$ ions changed the Zeta potential [45-47] and designed microparticles possessed a positive charge, as shown in Table 3.

Table 3. Quality evaluation of non-modified microparticles $C$ and cross-linked microparticles CA1 and CA2 containing MF.

\begin{tabular}{cccccc}
\hline Microparticles & $\begin{array}{c}\text { Zeta Potential } \\
(\mathbf{m V})\end{array}$ & $\begin{array}{c}\text { Production } \\
\text { Yield } \mathbf{( \% )}\end{array}$ & $\begin{array}{c}\text { Encapsulation } \\
\text { Efficiency } \mathbf{( \% )}\end{array}$ & $\begin{array}{c}\text { Loading } \\
\text { Percentage }(\%)\end{array}$ & $\begin{array}{c}\text { Particle Size } \\
(\boldsymbol{\mu m})\end{array}$ \\
\hline C & $-1.3 \pm 0.7$ & $61.7 \pm 2.1$ & $113.4 \pm 2.3$ & $75.6 \pm 1.5$ & $3.0 \pm 1.6$ \\
CA1 & $2.6 \pm 0.4$ & $57.1 \pm 1.6$ & $91.5 \pm 2.1$ & $77.1 \pm 1.7$ & $3.5 \pm 1.2$ \\
CA2 & $2.6 \pm 0.9$ & $56.1 \pm 2.4$ & $93.9 \pm 2.7$ & $73.9 \pm 3.4$ & $3.4 \pm 1.4$ \\
\hline
\end{tabular}

\subsection{Swelling and Mucoadhesive Properties}

The ALG swelling ability is a peculiar parameter affecting mucoadhesiveness and drug release. In contact with moisture, ALG begins to hydrate and swell, and as a consequence, forms a hydrogel which regulates the influx of the aqueous medium and drug dissolution [44]. As a result of gelling, the water influx is decreased; thus, the drug release is prolonged. Dissolution of freely water-soluble drugs from hydrophilic carriers is generally regulated by the drug's diffusive properties via the hydrogel matrix. Therefore, the swelling properties might significantly affect the drug release profiles [47].

The swelling behavior of designed microparticles was examined in an acidic environment and presented as the swelling ratio (SR), see Figure 3. At an acidic $\mathrm{pH}, \mathrm{ALG}$ carboxylate groups on the surface of the microparticles are protonated, and water-insoluble alginic acid is formed, which impedes the penetration of fluid into the deeper layers of the particle matrix [48,49]. After contact with this medium, non-modified ALG microparticles take up the fluid, which penetrates into the matrix and leads to an increase of SR to $180 \mathrm{~min}$. Formation of insoluble alginic acid leads to a limitation of swelling, and even shrinkage of particles, which was observed as a decreased SR of formulation $\mathrm{C}$ at $240 \mathrm{~min}$. $\mathrm{CaCl}_{2}$ cross-linked microparticles exhibited lower SR values than non-modified 
formulation C, and a linear increase up to $300 \mathrm{~min}$ was observed. The lower amount of swelling in cross-linked microparticles is the result of insoluble calcium alginate formation upon contact with the acidic medium, which leads to a lower water inflow into the matrix [48-50]. It was also found that microparticles CA1 and CA2 possessed higher values of SR, compared to the placebo formulations (PCA1 and PCA2), which is due to the occurrence of freely soluble molecules of MF and a faster influx of the aqueous medium into the microparticle structure.

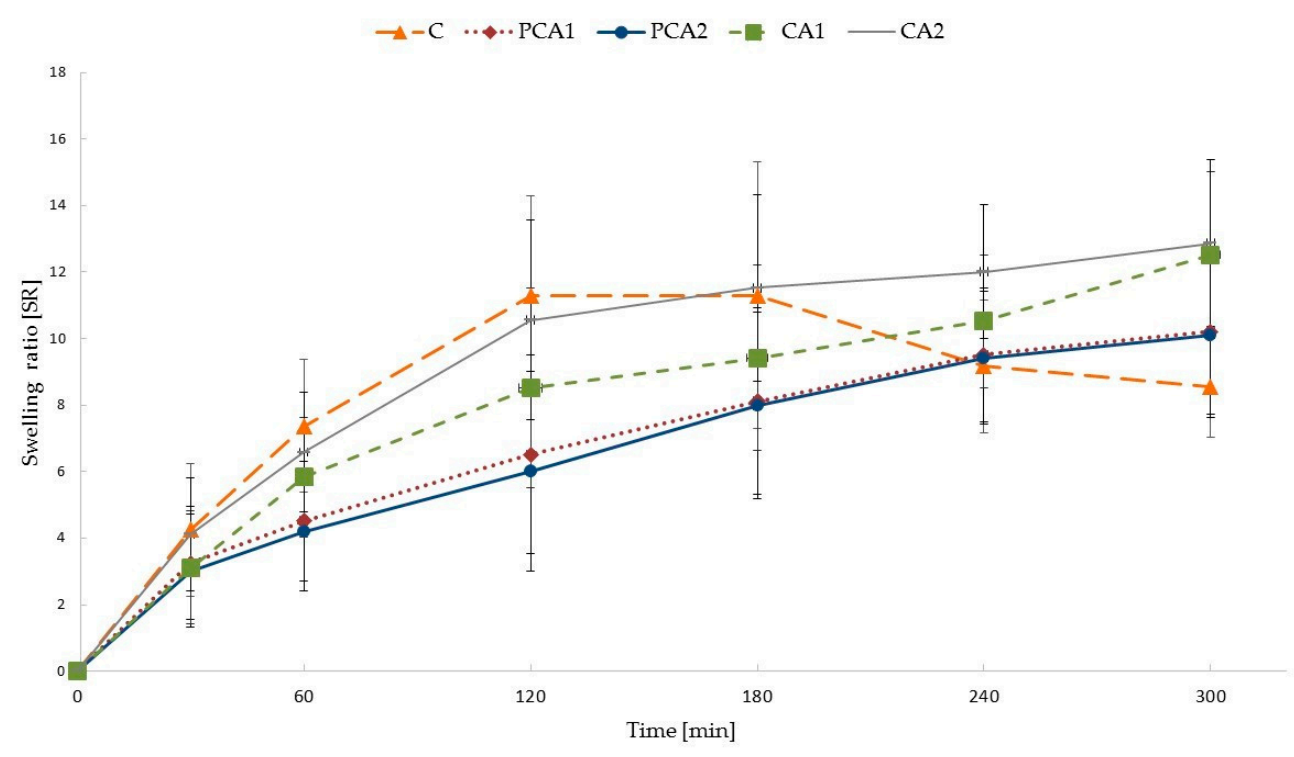

Figure 3. Swelling characteristics of non-modified C and cross-linked formulations PCA1, PCA2, CA1, and CA2.

The swelling process extends the contact time of the drug carrier with the mucosa and improves drug bioavailability. After contact with the hydrated mucus, ALG absorbs moisture and polymer chains with groups containing hydrogen bonds are relaxed [51]. This process, initiating deep contact of the polymer with the mucus layer enables the linkage of microparticles with mucosa and leads to the phenomenon of mucoadhesion [51,52]. Mucoadhesive properties of designed microparticles are presented in Table 4. All formulations adhered to tested materials, and mucoadhesiveness was considerably $(p<0.05)$ influenced by the type of adhesive layer, and the presence and concentration of $\mathrm{CaCl}_{2}$. When a gelatin disc and mucosa gel were used, similar values of $\mathrm{F}_{\max }$ and $\mathrm{W}_{\text {ad }} \mathrm{were}$ noted, as shown in Table 4 . In the case of porcine stomach mucosa, the highest $\mathrm{F}_{\max }$ values-median from $0.6 \mathrm{~N}(\mathrm{C})$ to $1.1 \mathrm{~N}(\mathrm{CA} 1)$ and $\mathrm{W}_{\text {ad }}$ values from $454.8 \mu \mathrm{J}(\mathrm{C})$ to $583.2 \mu \mathrm{J}(\mathrm{CA} 1)$-were observed, see Table 4 and Figure 4. Porcine stomach mucosa is a valuable model of the adhesive layer due to its similarity to human mucosa in terms of histology, ultrastructure, and composition, and it can be used to reflect the behavior of dosage forms in vivo [53]. It was demonstrated that in an acidic environment $\mathrm{CaCl}_{2}$ cross-linking reduces ALG interaction with the mucous membrane as a result of poor swelling ability [54-56]. However, in this study improvement of the mucoadhesieve properties of $\mathrm{CaCl}_{2}$ cross-linked ALG microparticles was observed. This fact can be explained by the presence of $\mathrm{Ca}^{2+}$ ions, which interact with the negatively charged mucin [57,58]. An increase in the positive charge of the polymer leads to better interactions with sialic acid and other anionic groups present in mucin and the formation of additional bonds with the negatively charged membrane $[59,60]$. With a higher concentration of cross-linking agent, increased work of adhesion was observed. Interestingly, freely water-soluble MF did not influence the mucoadhesive properties of the formulations. 
Table 4. Mucoadhesive properties of designed microparticles.

\begin{tabular}{|c|c|c|c|c|c|c|}
\hline \multirow{3}{*}{ Formulation } & \multicolumn{6}{|c|}{ Kind of Adhesive Material } \\
\hline & \multicolumn{2}{|c|}{ Gelatine Disc } & \multicolumn{2}{|c|}{ Mucin Gel } & \multicolumn{2}{|c|}{ Porcine Stomach Mucosa } \\
\hline & $F_{\max }(N)^{1}$ & $\mathrm{~W}_{\mathrm{ad}}(\mu \mathrm{J})^{2}$ & $F_{\max }(N)^{1}$ & $\mathrm{~W}_{\mathrm{ad}}(\mu \mathrm{J})^{2}$ & $F_{\max }(N)^{1}$ & $\mathrm{~W}_{\mathrm{ad}}(\mu \mathrm{J})^{2}$ \\
\hline Control $^{3}$ & $0.02 \pm 0.01$ & $15.2 \pm 0.7$ & $0.03 \pm 0.01$ & $18.1 \pm 3.5$ & $0.07 \pm 0.01$ & $29.4 \pm 3.3$ \\
\hline C & $0.5 \pm 0.2$ & $283.3 \pm 51.2$ & $0.6 \pm 0.3$ & $342.3 \pm 29.3$ & $0.6 \pm 0.2$ & $467.5 \pm 17.4$ \\
\hline PCA1 & $0.7 \pm 0.1$ & $291.3 \pm 14.4$ & $0.5 \pm 0.2$ & $362.9 \pm 18.8$ & $1.3 \pm 0.3$ & $519.7 \pm 16.9$ \\
\hline PCA2 & $0.6 \pm 0.2$ & $272.3 \pm 13.1$ & $0.5 \pm 0.1$ & $353.4 \pm 21.4$ & $1.2 \pm 0.1$ & $504.6 \pm 21.3$ \\
\hline CA1 & $0.7 \pm 0.2$ & $269.4 \pm 14.1$ & $0.6 \pm 0.2$ & $359.2 \pm 18.5$ & $1.1 \pm 0.7$ & $583.4 \pm 15.7$ \\
\hline CA2 & $0.6 \pm 0.1$ & $254.6 \pm 16.7$ & $0.7 \pm 0.3$ & $347.1 \pm 32.1$ & $1.3 \pm 0.2$ & $500.5 \pm 13.5$ \\
\hline
\end{tabular}

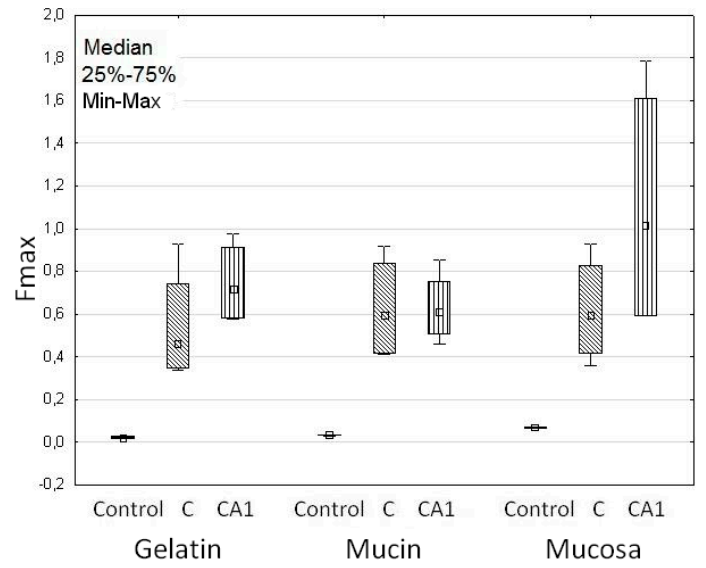

(a)

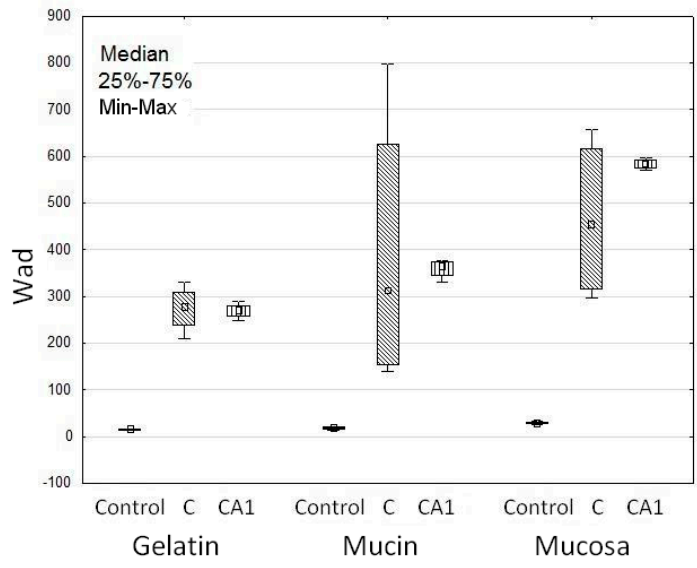

(b)

Figure 4. Mucoadhesive features: (a) Maximum detachment force $\left(\mathrm{F}_{\max }\right)$ and $(\mathrm{b})$ work of adhesion $\left(\mathrm{W}_{\mathrm{ad}}\right)$ of non-modified formulation $\mathrm{C}$, cross-linked formulation CA1 and cellulose paper (Control) (median; $\mathrm{n}=6$ ).

\subsection{MF Dissolution}

Dissolution of the active substance from microparticles depends on the drug's water solubility, influx of the medium into the structure of the dosage form, and polymer swelling [49,50]. In drug dissolution from all microparticles, a burst effect, caused by rapid dissolution of freely soluble MF bound at the microparticle surface, was noted and can be seen in Figure 5. Additionally, it was observed that MF was released faster from non-modified microparticles C $(82.5 \pm 3.6 \%$ MF was released after 2 h). This fact is related to the higher SR properties of the unmodified polymer in an acidic environment, which expedites the influx of the aqueous medium into the matrix. Modification of the ALG structure by $\mathrm{CaCl}_{2}$ affected MF dissolution-the release behavior from formulation CA2 (obtained with $0.05 \%$ of $\mathrm{CaCl}_{2}$ ) was comparable to non-modified microparticles $\mathrm{C}$, but formulation CA1 (with $0.1 \%$ of $\mathrm{CaCl}_{2}$ ) significantly prolonged MF release. It was shown that in formulation CA1 $60.1 \pm 3.8 \%$, MF was released in the first $2 \mathrm{~h}$ and sustained to $12 \mathrm{~h}$, whereby it reached $97.5 \pm 2.7 \% . \mathrm{Ca}^{2+}$ cross-linking leads to a more stable and more intact structure, improves the mechanical resistance of the polymeric network, and reduces its swelling ability [61]. 


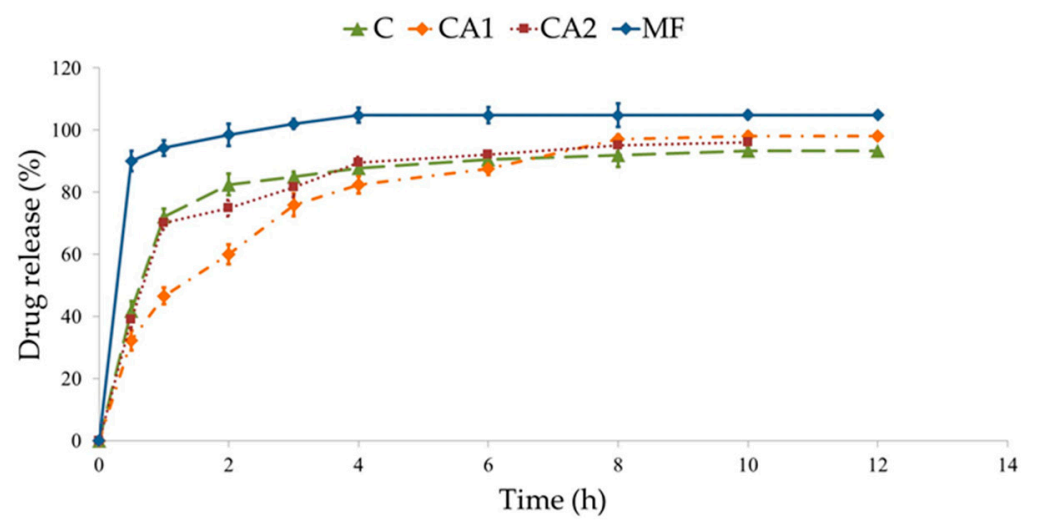

Figure 5. MF dissolution from non-modified microparticles C, cross-linked CA1, CA2, and commercial product used as a control (MF).

MF dissolution was also analyzed by different mathematical equations, see Table 5. It was shown that from designed microparticles, MF was released according to first-order kinetics. In the model of Highuchi, where the best-fit curve with a high $\mathrm{R}^{2}$ was observed, it was proved that MF release was diffusion controlled. In the model of Korsmeyer-Peppas, values of index $n$ were from 0.08 to 0.12 and confirmed diffusion-dependent MF dissolution. In comparison to formulation C, the Hixson-Crowell model exhibited a better linear relationship with a regression index from 0.94 to 0.96 , indicating that the dominant mechanism of MF release from modified microparticle formulations is diffusion coupled with erosion determined by the presence of a cross-linking agent [62].

Table 5. Mathematical characteristics of MF dissolution.

\begin{tabular}{|c|c|c|c|c|c|c|c|c|c|c|c|}
\hline \multirow[b]{3}{*}{ Formulation } & \multicolumn{11}{|c|}{ Mathematical Model } \\
\hline & \multicolumn{2}{|c|}{ Zero Order } & \multicolumn{2}{|c|}{ First Order } & \multicolumn{2}{|c|}{ Highuchi } & \multicolumn{3}{|c|}{ Korsmeyer-Peppas } & \multicolumn{2}{|c|}{ Hixson-Crowel } \\
\hline & $\mathbf{R}^{2}$ & K & $\mathbf{R}^{2}$ & K & $\mathbf{R}^{2}$ & K & $\mathbf{R}^{2}$ & K & $n$ & $\mathbf{R}^{2}$ & K \\
\hline C & 0.52 & 4.62 & 0.73 & 0.21 & 0.66 & 18.76 & 0.59 & 0.28 & 0.12 & 0.65 & 0.19 \\
\hline CA1 & 0.86 & 1.68 & 0.96 & 0.55 & 0.95 & 29.37 & 0.88 & 0.34 & 0.08 & 0.94 & 0.58 \\
\hline CA2 & 0.92 & 1.67 & 0.98 & 0.17 & 0.97 & 22.98 & 0.94 & 0.31 & 0.08 & 0.96 & 0.18 \\
\hline
\end{tabular}

$\mathrm{R}^{2}$ : correlation coefficient, $\mathrm{K}$ : dissolution constant, $\mathrm{n}$ : the dissolution index

During the design of oral formulations, it is crucial to explain the drug release mechanism, but also to evaluate if the development of a new technological process affects the modification of the drug release profile compared to the conventional dosage form. Therefore, the similarity and dissimilarity factors were determined to measure the similarity of MF dissolution profiles and to express the potential product similarity [63]. The difference and similarity indices $f_{1}$ and $f_{2}$, following the international (FDA, EMA) guidelines for the dissolution profile comparison were used $[64,65]$. According to these guidelines, release profiles are comparable if they possess a value of $f_{1}$ in the range $0-15$ and $f_{2}$ in the range $50-100$ [66].

MF release profiles of formulations CA1 and CA2 were compared with non-modified formulation $\mathrm{C}$ and a commercial product with non-modified MF release was used as a reference sample. When a non-modified tablet containing MF was used as a control, it was observed that all designed formulations have a similarity factor of $<50$ and difference factor of $>15$. Therefore, it was concluded that both non-modified microparticles and formulations modified by $\mathrm{CaCl}_{2}$ were characterized by different drug release profiles. To assess the impact of a cross-linking agent on the MF dissolution process, an independent model approach was applied. It was found that in formulation CA2, values of difference and similarity factors were 4.05 and 72.27, respectively, which indicates a similar MF dissolution profile to formulation C. On the other hand, the formulation CA1 was characterized by the 
difference factor 17.55 and similarity factor 42.88 , which indicates that $\mathrm{CaCl}_{2}$ concentration affected MF dissolution.

\subsection{Differential Scanning Calorimetry (DSC)}

To evaluate the thermal characteristics of the materials and excipients used, DSC technology was utilized [67]. The MF thermogram exhibits a sharp endothermic peak at $233.02{ }^{\circ} \mathrm{C}$, which corresponds to the melting point of pure MF, see Figure 6. The DSC curves of ALG and PCA1 were similar, and broad endothermal peaks between $100{ }^{\circ} \mathrm{C}$ and $150^{\circ} \mathrm{C}$ were observed, which indicates the loss of water content in the polymer. Additionally, a sharp exothermic peak related to ALG decomposition at $248^{\circ} \mathrm{C}$ was observed. The thermogram of PCA1 shows an exothermic peak registered at $252.6^{\circ} \mathrm{C}$, which might suggest an interaction between $\mathrm{CaCl}_{2}$ and ALG. On the other hand, the MF peak demonstrated a slight decrease in the melting temperature in the CA1 formulation $\left(218.13^{\circ} \mathrm{C}\right)$ in comparison to $\mathrm{MF}$ $\left(226.57^{\circ} \mathrm{C}\right)$, which is probably as a result of interactions between $\mathrm{MF}$ and the polymer, and formation of prim polymer matrix [68].

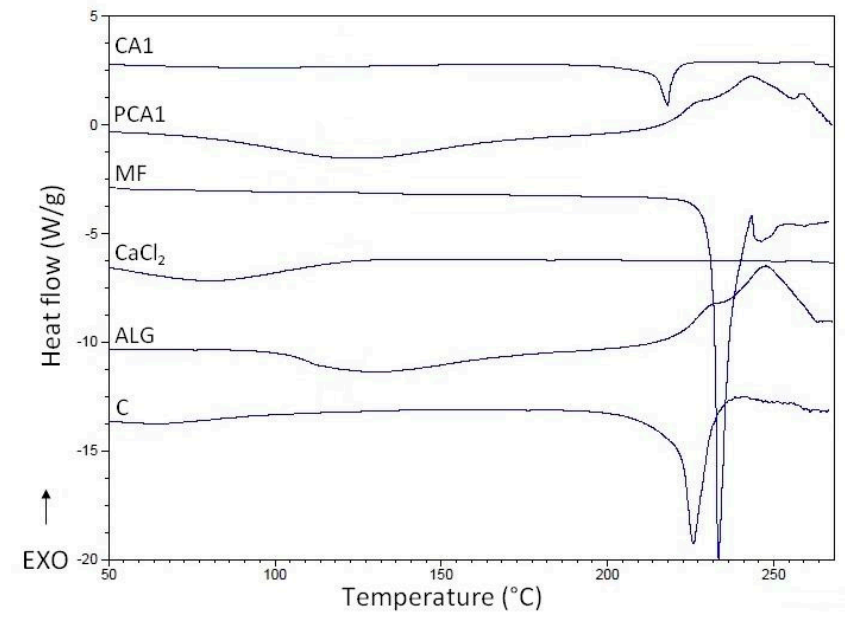

Figure 6. Differential scanning calorimetry (DSC) curves of pure sodium alginate (ALG), metformin (MF), $\mathrm{CaCl}_{2}$, non-modified microparticles $\mathrm{C}$, microparticles PCA1, and CA1.

\section{Conclusions}

Drug solubility exerts an evident impact on the mechanism and release kinetics. The rapid dissolution of active compounds characterized by being freely soluble in water is one of the main drawbacks when designing pharmaceutical formulations. To prolong the release of MF used as a model freely water-soluble drug, physical modification of ALG microparticles by $\mathrm{CaCl}_{2}$ cross-linking using a novel one-step drying process was applied. The developed method involves considerably fewer unit operations than traditional emulsification techniques. The in vitro drug release data showed a significant difference among cross-linked and non-cross-linked formulations. This study demonstrates that $\mathrm{CaCl}_{2}$ cross-linked ALG microparticles can be successfully used to prolong MF release. Additionally, it was observed that ALG cross-linking using $\mathrm{CaCl}_{2}$ decreased the swelling ratio and improved the mucoadhesive properties of microparticles evaluated using porcine stomach mucosa.

Author Contributions: Conceptualization, M.S. and K.W.; Data curation, K.S. and A.C.-K.; Investigation, M.S.; Methodology, M.S., K.S., A.C.-K. and K.W.; Project administration, M.S.; Software, K.S. and A.C.-K.; Supervision, K.W.; Writing-original draft, M.S.; Writing-review \& editing, K.W. M.S. conducted the research and collected the data. K.S. accomplished the statistical analysis. A.C.-K. performed the dissolution tests. K.W. and M.S. developed the research, resolved the results and wrote the article.

Funding: This research and the APC were funded by Medical University of Białystok grant number N/ST/ZB/17/007/2215. 
Acknowledgments: Equipment used in this study was from OP DEP 2007-2013, Priority Axis I.3, contract No. POPW.01.03.00-20-008/09. Research was financed by Medical University of Białystok grant $\mathrm{N} / \mathrm{ST} / \mathrm{ZB} / 17 / 007 / 2215$.

Conflicts of Interest: No conflict of interest is declared.

\section{References}

1. Huang, G.; Mei, X.; Xiao, F.; Chen, X.; Tang, Q.; Peng, D. Applications of important polysaccharides in drug delivery. Curr. Pharm. Des. 2015, 25, 3692-3696. [CrossRef]

2. Asada, T.; Yoshihara, N.; Ochiai, Y.; Kimura, S.I.; Iwao, Y.; Itai, S. Formulation of a poorly water-soluble drug in sustained-release hollow granules with a high viscosity water-soluble polymer using a fluidized bed rotor granulator. Int. J. Pharm. 2018, 541, 246-252. [CrossRef] [PubMed]

3. Chakraborty, S.; Khandai, M.; Sharma, A.; Patra, C.N.; Patro, V.J.; Sen, K.K. Effects of drug solubility on the release kinetics of water soluble and insoluble drugs from HPMC based matrix formulations. Acta Pharm. 2009, 59, 313-323. [CrossRef] [PubMed]

4. Boddupalli, B.M.; Mohammed, Z.N.K.; Nath, R.A.; Banji, D. Mucoadhesive drug delivery system: An overview. J. Adv. Pharm. Technol. Res. 2010, 1, 381-387. [CrossRef] [PubMed]

5. Mythri, G.; Kavitha, K.; Kumar, M.R.; Jagadeesh Singh, S.D. Novel mucoadhesive polymers-A review. J. App. Pharm. Sci. 2011, 1, 37-42.

6. Patwekar, S.; Baramade, M.K. Controlled release approach to novel multiparticulate drug delivery system. Int. J. Pharm. Pharm. Sci. 2012, 4, 757-763.

7. Dey, N.S.; Majumdar, S.; Rao, M.E.B. Multiparticulate drug delivery systems for controlled release. Trop. J. Pharm. Res. 2008, 7, 1067-1075. [CrossRef]

8. Sachan, K.N.; Pushkar, S.; Jha, A.; Bhattcharya, A. Sodium alginate: The wonder polymer for controlled drug delivery. J. Pharm. Res. 2009, 2, 1191-1199.

9. Laurienzo, P. Marine polysaccharides in pharmaceutical applications: An overview. Mar. Drugs 2010, 8, 2435-2465. [CrossRef] [PubMed]

10. Wong, T.W. Alginate graft copolymers and alginate-co-excipient physical mixture in oral drug delivery. J. Pharm. Pharmacol. 2011, 63, 1497-1512. [CrossRef] [PubMed]

11. Murata, Y.; Jinno, D.; Liu, D.; Isobe, T.; Kofuji, K.; Kawashima, S. The drug release profile from calcium-induced alginate gel beads coated with an alginate hydrolysate. Molecules 2007, 12, 2559-2566. [CrossRef] [PubMed]

12. Kim, E.S.; Lee, J.S.; Lee, H.G. Calcium-alginate microparticles for sustained release of catechin prepared via an emulsion gelation technique. Food Sci. Biotechnol. 2016, 25, 1337-1343. [CrossRef]

13. Lira, A.A.; Rossetti, F.C.; Nanclares, D.M.; Neto, A.F.; Bentley, M.V.; Marchetti, J.M. Preparation and characterization of chitosan-treated alginate microparticles incorporating all-trans retinoic acid. J. Microencapsul. 2009, 26, 243-250. [CrossRef] [PubMed]

14. Szekalska, M.; Puciłowska, A.; Szymańska, E.; Ciosek, P.; Winnicka, K. Alginate: Current use and future perspectives in pharmaceutical and biomedical applications. Int. J. Polym. Sci. 2016, 2016. [CrossRef]

15. Agüero, A.; Zaldivar-Silva, D.; Peña, L.; Dias, M.L. Alginate microparticles as oral colon drug delivery device: A review. Carbohydr. Polym. 2017, 168, 32-43. [CrossRef] [PubMed]

16. Sarei, F.; Dounighi, N.M.; Zolfagharian, H.; Khaki, P.; Bidhendi, S.M. Alginate nanoparticles as a promising adjuvant and vaccine delivery system. Indian J. Pharm. Sci. 2013, 75, 442-449. [CrossRef] [PubMed]

17. Venkatesan, J.; Bhatnagar, I.; Manivasagan, P.; Kang, K.H.; Kim, S.K. Alginate composites for bone tissue engineering: A review. Int. J. Biol. Macromol. 2015, 72, 269-281. [CrossRef] [PubMed]

18. Sun, J.; Tan, H. Alginate-based biomaterials for regenerative medicine applications. Materials 2013, 6, 1285-1309. [CrossRef] [PubMed]

19. Khanna, O.; Larson, J.C.; Moya, M.L.; Opara, E.C.; Brey, E.M. Generation of alginate microspheres for biomedical applications. J. Vis. Exp. 2012, 66, 3388. [CrossRef] [PubMed]

20. Nagpal, M.; Maheshwari, D.; Rakha, P.; Dureja, H.; Goyal, S.; Dhingra, G. Formulation development and evaluation of alginate microspheres of ibuprofen. J. Young Pharm. 2012, 4, 13-16. [CrossRef] [PubMed] 
21. Ahmed, M.M.; El-Rasoul, S.A.; Auda, S.H.; Ibrahim, M.A. Emulsification/internal gelation as a method for preparation of diclofenac sodium-sodium alginate microparticles. Saudi Pharm. J. 2013, 21, 61-69. [CrossRef] [PubMed]

22. Shukla, S.; Jain, D.; Verma, K.; Verma, S. Formulation and in vitro characterization of alginate microspheres loaded with diloxanide furoate for colon-specific drug delivery. Asian J. Pharm. 2010, 6, 199-204.

23. Suganya, V.; Anuradha, V. Microencapsulation and nanoencapsulation: A review. Int. J. Pharm. Clin. Res. 2017, 9, 233-239. [CrossRef]

24. Giri, T.K.; Choudhary, C.; Alexander, A.; Badwaik, H.; Tripathi, D.K. Prospects of pharmaceuticals and biopharmaceuticals loaded microparticles prepared by double emulsion technique for controlled delivery. Saudi Pharm. J. 2013, 21, 125-141. [CrossRef] [PubMed]

25. Sosnik, A.; Seremeta, K.P. Advantages and challenges of the spray-drying technology for the production of pure drug particles and drug-loaded polymeric carriers. Adv. Colloid Interfacce Sci. 2015, 223, 40-54. [CrossRef] [PubMed]

26. Patel, B.B.; Patel, J.K.; Chakraborty, S. Review of patents and application of spray drying in pharmaceutical, food and flavor industry. Recent Pat. Drug Deliv. Formul. 2014, 8, 63-78. [CrossRef] [PubMed]

27. Bagheri, L.; Madadlou, A.; Yarmand, M.; Mousavi, M.E. Spray-dried alginate microparticles carrying caffeine-loaded and potentially bioactive nanoparticles. Food Res. Int. 2014, 62, 1113-1119. [CrossRef]

28. Santa-Maria, M.; Scher, H.; Jeoh, T. Microencapsulation of bioactives in cross-linked alginate matrices by spray drying. J. Microencapsul. 2012, 29, 286-295. [CrossRef] [PubMed]

29. Foretz, M.; Guigas, B.; Bertrand, L.; Pollak, M.; Viollet, B. Metformin: From mechanisms of action to therapies. Cell Metab. 2014, 20, 953-966. [CrossRef] [PubMed]

30. Szekalska, M.; Wróblewska, M.; Sosnowska, K.; Winnicka, K. Influence of sodium alginate on hypoglycemic activity of metformin hydrochloride in the microspheres obtained by the spray drying. Int. J. Polym. Sci. 2016, 2016. [CrossRef]

31. Kulig, D.; Zimoch-Korzycka, A.; Jarmoluk, A.; Marycz, K. Study on alginate-chitosan complex formed with different polymers ratio. Polymers 2016, 8, 167. [CrossRef]

32. León, O.; Muñoz-Bonilla, A.; Soto, D.; Pérez, D.; Rangel, M.; Colina, M.; Fernández-García, M. Removal of anionic and cationic dyes with bioadsorbent oxidized chitosans. Carbohydr. Polym. 2018, 194, 375-383. [CrossRef] [PubMed]

33. Szymańska, E.; Winnicka, K.; Amelian, A.; Cwalina, U. Vaginal chitosan tablets with clotrimazole-design and evaluation of mucoadhesive properties using porcine vaginal mucosa, mucin and gelatin. Chem. Pharm. Bull. 2014, 62, 160-167. [CrossRef] [PubMed]

34. Council of Europe. The European Pharmacopeia, 9th ed.; Council of Europe: Strasburg, France, 2016; Volume 1, p. 302.

35. Costa, P.; Sousa Lobo, J.M. Modeling and comparison of dissolution profiles. Eur. J. Pharm. Sci. 2001, 13, 123-133. [CrossRef]

36. Siepmann, J.; Peppas, N.A. Modeling of drug release from delivery systems based on hydroxypropyl methylcellulose (HPMC). Adv. Drug Deliv. Rev. 2001, 48, 139-157. [CrossRef]

37. Soni, T.; Nagda, C.; Gandhi, T.; Chotai, N.P. Development of discriminating method for dissolution of aceclofenac marketed formulations. Dissolut. Technol. 2008, 15, 31-35. [CrossRef]

38. Diaz, D.D.; Colgan, S.T.; Langer, C.S.; Bandi, N.T.; Likar, M.D.; Alstine, L.V. Dissolution similarity requirements: How similar or dissimilar are the global regulatory expectations? AAPS J. 2016, 18, 15-22. [CrossRef] [PubMed]

39. Gray, V.; Kelly, G.; Xia, M.; Butler, C.; Thomas, S.; Mayock, S. The Science of USP 1 and 2 dissolution: Present challenges and future relevance. Pharm. Res. 2009, 26, 1289-1302. [CrossRef] [PubMed]

40. Mazurek-Wądołkowska, E.; Winnicka, K.; Czajkowska-Kośnik, A.; Czyżewska, U.; Miltyk, W. Application of differential scanning calorimetry in evaluation of solid state interactions in tablets containing acetaminophen. Acta Pol. Pharm. 2013, 70, 787-793. [PubMed]

41. Santana, A.A.; Kieckbusch, T.G. Physical evaluation of biodegradable films of calcium alginate plasticized with polyols. Braz. J. Chem. Eng. 2013, 30, 835-884. [CrossRef]

42. Mandal, S.; Basu, S.K.; Sa, B. Sustained release of a water-soluble drug from alginate matrix tablets prepared by wet granulation method. AAPS PharmSciTech 2009, 10, 1348-1356. [CrossRef] [PubMed] 
43. Jain, D.; Bar-Shalom, D. Alginate drug delivery systems: Application in context of pharmaceutical and biomedical research. Drug Dev. Ind. Pharm. 2014, 40, 1576-1584. [CrossRef] [PubMed]

44. Colombo, P.; Bettini, R.; Santi, P.; Peppas, N.A. Swellable matrices for controlled drug delivery: Gel-layer behaviour, mechanisms and optimal performance. Pharm. Sci. Technol. Today 2000, 3, 198-204. [CrossRef]

45. Clogston, J.D.; Patri, A.K. Zeta potential measurement. Methods Mol. Biol. 2011, 697, 63-70. [CrossRef] [PubMed]

46. Sriamornsak, P.; Konthong, S.; Nunthanid, J. Fabrication of calcium pectinate microparticles from pomelo pectin by ionotropic gelation. JAASP. J. 2012, 1, 203-209.

47. Li, H.; Hardy, R.J.; Gu, X. Effect of drug solubility on polymer hydration and drug dissolution from polyethylene oxide (PEO) matrix tablets. AAPS PharmSciTech 2008, 9, 437-443. [CrossRef] [PubMed]

48. Qin, Y.; Hu, H.; Luo, A. The conversion of calcium alginate fibers into alginic acid fibers and sodium alginate fibers. J. Appl. Polym. Sci. 2006, 101, 4216-4221. [CrossRef]

49. Rojewska, M.; Olejniczak-Rabinek, M.; Bartkowiak, A.; Snela, A.; Prochaska, K.; Lulek, J. The wettability and swelling of selected mucoadhesive polymers in simulated saliva and vaginal fluids. Colloids Surf. B Biointerfaces 2017, 156, 366-374. [CrossRef] [PubMed]

50. Daemi, H.; Barikani, M. Synthesis and characterization of calcium alginate nanoparticles, sodium homopolymannuronate salt and its calcium nanoparticles. Sci. Iran. 2012, 19, 2023-2028. [CrossRef]

51. Shaikh, R.; Raj Singh, T.R.; Garland, M.J.; Woolfson, A.D.; Donnelly, R.F. Mucoadhesive drug delivery systems. J. Pharm. Bioallied Sci. 2011, 3, 89-100. [CrossRef] [PubMed]

52. Agarwal, S.; Aggarwal, S. Mucoadhesive polymeric platform for drug delivery; a comprehensive review. Curr. Drug Deliv. 2015, 12, 139-156. [CrossRef] [PubMed]

53. Jackson, S.J.; Perkins, A.C. In vitro assessment of the mucoadhesion of cholestyramine to porcine and human gastric mucosa. Eur. J. Pharm. Biopharm. 2001, 52, 121-127. [CrossRef]

54. Abdelbary, A.; El-Gazayerly, O.N.; El-Gendy, N.A.; Ali, A.A. Floating tablet of trimetazidine dihydrochloride: An approach for extended release with zero-order kinetics. AAPS PharmSciTech 2010, 11, 1058-1067. [CrossRef] [PubMed]

55. Segale, L.; Giovannelli, L.; Mannina, P.; Pattarino, F. Calcium alginate and calcium alginate-chitosan beads containing celecoxib solubilized in a self-emulsifying phase. Scientifica 2016, 2016. [CrossRef] [PubMed]

56. Davidovich-Pinhas, M.; Bianco-Peled, H. A quantitative analysis of alginate swelling. Carbohydr. Polym. 2010, 79, 1020-1027. [CrossRef]

57. Shtenberg, Y.; Goldfeder, M.; Prinz, H.; Shainsky, J.; Ghantous, Y.; Abu El-Naaj, I.; Schroeder, A.; Bianco-Peled, H. Mucoadhesive alginate pastes with embedded liposomes for local oral drug delivery. Int. J. Biol. Macromol. 2018, 111, 62-69. [CrossRef] [PubMed]

58. Zhang, Z.H.; Sun, Y.S.; Pang, H.; Munyendo, W.L.; Lv, H.X.; Zhu, S.L. Preparation and evaluation of berberine alginate beads for stomach-specific delivery. Molecules 2011, 14, 10347-10356. [CrossRef] [PubMed]

59. Pawar, V.K.; Kansal, S.; Garg, G.; Awasthi, R.; Singodia, D.; Kulkarni, G.T. Gastroretentive dosage forms: A review with special emphasis on floating drug delivery systems. Drug Deliv. 2011, 18, 97-110. [CrossRef] [PubMed]

60. Lehr, C.M.; Bouwstra, J.A.; Schacht, E.H.; Junginger, H.E. In vitro evaluation of mucoadhesive properties of chitosan and some other natural polymers. Int. J. Pharm. 1992, 78, 43-48. [CrossRef]

61. Mi, F.L.; Sung, H.W.; Shyu, S.S. Drug release from chitosan-alginate complex microcapsules reinforced by a naturally occurring cross-linking agent. Carbohydr. Polym. 2002, 48, 61-72. [CrossRef]

62. Stevenson, C.L.; Bennett, D.B.; Lechuga-Ballesteros, D. Pharmaceutical liquid crystals: The relevance of partially ordered systems. J. Pharm. Sci. 2005, 94, 1861-1880. [CrossRef] [PubMed]

63. Shirkhorshidi, A.S.; Aghabozorgi, S.; Wah, T.Y. A comparison study on similarity and dissimilarity measures in clustering continuous data. PLoS ONE 2015, 10, e0144059. [CrossRef] [PubMed]

64. Department of Health and Human Services, Food and Drug Administration, Center for Drug Evaluation and Research (CDER), U.S. Government Printing Office. Extended Release Oral Dosage Forms: Development, Evaluation, and Application of In Vitro/In Vivo Correlations; Guidance for Industry; Department of Health and Human Services, Food and Drug Administration, Center for Drug Evaluation and Research (CDER), U.S. Government Printing Office: Washington, DC, USA, 1997. Available online: https:/ /www.fda.gov/ downloads/drugs / guidances/ucm070239.pdf.U.S (accessed on 10 June 2018). 
65. European Medicines Agency. Investigation of Bioequivalence; European Medicines Agency: London, UK, 29 January 2010.

66. Gohel, M.C.; Sarvaiya, K.G.; Mehta, N.R.; Soni, C.D.; Vyas, V.U.; Dave, R.K. Assessment of similarity factor using different weighting approaches. Dissolut. Technol. 2005, 12, 22-37. [CrossRef]

67. Soares, J.P.; Santos, J.E.; Chierice, G.O.; Cavalheiro, E.T.G. Thermal behavior of alginic acid and its sodium salt. Eclética Química 2004, 2, 53-56. [CrossRef]

68. Mucha, M.; Pawlak, A. Thermal analysis of chitosan and its blends. Thermochim. Acta 2005, 427, 69-76. [CrossRef]

(C) 2018 by the authors. Licensee MDPI, Basel, Switzerland. This article is an open access article distributed under the terms and conditions of the Creative Commons Attribution (CC BY) license (http://creativecommons.org/licenses/by/4.0/). 